\title{
A invenção da Argentina: história de uma ideia
}

The invention of Argentina

Geraldo Houly Lelis de Freitas* geraldolelisjr@gmail.com

Resumo: Este texto propõe resenhar a obra $A$ invenção da Argentina de Nicolas Shumway, prêmio "livro notável do ano" pela revista norte americana The New York Times em 1991, premiado também pela Latin American Studies Association (Lasa) em 1992. Tendo como base uma extensa e rigorosa pesquisa acerca dos intelectuais, escritores e políticos do século XIX, a sua tese compreende que o processo de construção da identidade do povo argentino foi obstaculizado, desde a colonização espanhola, pelas divergências e pelos conflitos político-econômicos entre o privilegiado Buenos Aires e a região interiorana.

Palavras-chave: Nacionalismo, invenção, identidade

Abstract: This text proposes a review of the book The Invention of Argentina of Nicolas Shumway, prize Notable Book of the Year'for the North American magazine The New York Times in 1991, also rewarded for the Association of Latin American Studies (Lasa) in 1992. Taking an extensive and rigorous inquiry as a base about the intellectuals, writers and politicians of the century XIX, his theory understands that the process of construction the identity of the Argentine people was hampered, from the Spanish colonization, by the divergences and by the conflicts economical-politically between the privileged Buenos Aires and countryside.

Keywords: Nationalism, invention, identify 
Este trabalho tem por proposta uma resenha crítica referente à obra $A$ invenção da Argentina de Nicolas Shumway. O autor nasceu na Reserva de Navajo, entretanto, foi criado em Saint Johns, Arizona. Concluiu o mestrado em 1971 e o doutorado em 1976 pela Universidade de Califórnia. Estudioso em temas de literatura e de linguística hispânica. Professor pela Rice University, desde 2010. Além da língua americana, fluente no espanhol e no português. Em 1999, convidado pela Universidade de São Paulo (USP) para ministrar a disciplina Romance Histórico Hispano-americano; em 2002, novamente pela USP, lecionou na pós-graduação a disciplina $A$ invenção dos Estados Unidos da América (EUA). A obra $A$ invenção da Argentina teve a sua primeira edição em 1991. Neste mesmo ano, recebeu o prêmio de "livro notável do ano" da revista norte americana The New York Times. Em 1992, recebeu o segundo prêmio de reconhecimento da Latin American Studies Association (Lasa). A obra foi traduzida para a língua espanhola em 1993, ganhou uma versão ampliada e revisada no ano de 2004. Para a língua portuguesa, a tradução só foi finalizada em 2008. Todas acompanhadas pessoalmente pelo autor.

De antemão, Nicolas Shumway deixa bem claro, sendo norte americano, não é o seu objetivo explicar a história da Argentina para os argentinos. O propósito inicial é apresentar aos leitores da língua inglesa a oportunidade de conhecer a história desse país, particularmente, de sua invenção. Após extensa e rigorosa pesquisa nos arquivos públicos da Argentina, a obra foi organizada em dez capítulos dedicados em sua maioria ao estudo do conjunto de intelectuais, escritores e políticos do século XIX que contribuíram cada um ao seu modo no processo de construção da identidade do povo argentino.

Pode-se dizer que a "onda nacionalista", na Argentina, não foi um fenômeno isolado, mas fez parte de uma realidade histórica mundial, no qual incluiu inúmeros países latinos americanos (e também europeus). Apesar do debate historiográfico acerca da "fabricação" da nacionalidade Argentina não seja tão recente, a contribuição do historiador Eric Hobsbawm a esse respeito é esclarecedora, segundo o qual: "na verdade, a política no novo sentido o século XIX era, basicamente, uma política de dimensões nacionais. Em suma, para fins práticos, a sociedade ('sociedade civil') e o Estado em que ela funcionava tornaram-se cada vez mais inseparáveis" (HOBSBAWM, 1997, p. 272-3).

Cabe ressaltar que o termo "invenção", segundo a proposta da obra, não pode ser interpretado como fruto de uma criação idealista, ou construído a partir de um nada. A invenção da identidade nacional apresentase como produto de forças estruturais consolidadas ao longo do tempo pela própria dinâmica do sistema capitalista. Sem dúvida, Nicolas Shumway elegeu as estruturas política e econômica para explicar os fundamentos de sua tese, a princípio, pela compreensão das relações de poder entre os representantes de Buenos Aires, os portenhos, e os do interior, os caudilhos.

\section{Ficção-diretriz: quem não é argentino}

Antes de ir para a sua pesquisa de campo na Argentina, Nicolas Shumway revelou que pretendia "escrever uma história intelectual do período de quinze anos entre o Golpe de 1930 (o primeiro da Argentina no século XX) e a vitória de Juan Domingo Perón, em 1945” (SHUMWAY, 2008, p. 15). O propósito do trabalho seria "reconstituir as correntes intelectuais que anteciparam o peronismo e explicar em certa medida a extraordinária polarização que desde então dominou o país" (SHUMWAY, 2008, p. 15).

Contudo, as fontes históricas reunidas o levaram a mudar não só a sua concepção de análise, mas também o objeto de estudo que passou a ser "as primeiras 
ficções-diretrizes argentinas tal como aparecem na obra de escritores e pensadores mais importantes do país, entre 1808 e 1880 [...] apesar de algumas incursões na história social, mantive o foco da discussão nas ideias relevantes para a criação de uma identidade nacional e sua interação com a história [...] não é um estudo da história intelectual argentina [...] uma análise detalhada do pensamento argentino contemporâneo escapa à esfera deste livro" (SHUMWAY, 2008, p. 18-9).

A opção de Shumway, para o estudo aprofundado do século anterior ao pretendido, justifica-se, uma vez que o fenômeno histórico da invenção das nacionalidades, como já foi abordado, surge em larga escala no século XIX.

A principal influência metodológica de Nicolas Shumway foi o professor de história da Yale University, Edmund Morgan, autor do clássico Inventing the people (1988). Nesta obra, Edmund Morgan propôs uma reflexão teórica sobre como funcionava a idealização da "representação" do sistema político federativo norte americano. Em síntese, o autor relaciona a "representação" como ficção-diretriz que atuava de forma "necessária" e "positiva", ou seja, "necessária" porque a crença de que o governo representa os interesses dos cidadãos os levam a obedecer às leis com uma coerção mínima e, "positiva" porque nada promoveu tanto as reformas como o esforço para que a realidade coincida com a ficção-diretriz.

Nesse sentido, Nicolas Shumway parte do pressuposto indicado pelo pensamento de Edmund Morgan acerca da relação entre o conceito de ficção-diretriz e a “mitologia da exclusão", isto é, o processo de invenção da nacionalidade não tem origem no que lhe é identificatório, mas no que não lhe é identificatório. A invenção do nacionalismo argentino não tinha, a princípio, o propósito de identificar quem eram os argentinos, mas quem não o era. Essa política de exclusão tem relação com a expansão do processo democrático e da cidadania (direitos políticos, sociais) no século XIX. Novamente, Eric Hobsbawm contribui para a compreensão dessa questão: "a ampliação do progresso da democracia eleitoral e a consequente aparição da política de massas, portanto, dominaram a invenção das tradições no período de 1870-1914” (HOBSBAWM, 1997, p. 275).

\section{Dicotomias entre Buenos Aires e interior}

Para alcançar o seu objetivo, Nicolas Shumway procurou compreender a dinâmica das relações econômicas burguesas entre Buenos Aires e interior, desde a sua consolidação, ainda no período de colonização espanhola. O privilégio comercial histórico da província de Buenos Aires era não apenas, pelo fato, de possuir os pampas (as melhores terras cultiváveis em toda a Argentina), como também do acesso estratégico ao oceano para a troca e o transporte de mercadorias com outros povos.

O porto de Buenos Aires monopolizava as importações e as exportações em toda a região da Prata, que se estendia além do que representa o território da Argentina hoje. Essa concentração de riquezas teria levado a necessidade da Coroa espanhola em admitir a criação do Vice-Reinado em Buenos Aires. O objetivo era aumentar o controle sobre a arrecadação real derivado da cobrança de impostos sobre as transações comerciais, em troca, assegurar-se-ia a concentração de riquezas e a acumulação de capital nas mãos das burguesias portenha e espanhola. O dispositivo de poder real na província de Buenos Aires teve a sua fundação a partir da autonomia concedida pelo monarca espanhol Carlos III, em 1776, ao autorizar a criação do ViceReinado do Rio da Prata, junto com a autoridade de cobrar e de repassar à metrópole as taxas aduaneiras. Sem dúvida, o Vice-Reinado que deliberava na função de Estado tinha a finalidade de legitimar toda essa relação 
de concentração de riquezas e de poder entre poucos intervenientes privilegiados na metrópole e na colônia.

Sobre a formação das redes de comércio do Rio da Prata durante o período colonial, os judeus e os cristãos novos tiveram grande influência, inclusive com um sistema de trocas ilegais (que passava pelos portos brasileiros) formado por fugitivos da Inquisição portuguesa e espanhola. Nesse sentido, Nicolas Shumway apresenta o primeiro limite de sua pesquisa, pois não faz qualquer menção e nem relaciona esses comerciantes com a formação das burguesias argentina. Apenas se restringiu a citar o interesse da Coroa em obter um maior controle do comércio ilegal.

\begin{abstract}
A motivação fundamental da Coroa era exercer, por meio de uma política chamada ironicamente de libre comercio, maior controle sobre as exportações, em especial de prata boliviana em barras, que se realizava de forma ilegal há quase meio século. Os astutos comerciantes de Buenos Aires não tardaram a firmar contratos de exclusividade com os monopólios mercantis espanhóis, formando assim a base de algumas das fortunas particulares mais antigas da Argentina. Além da prata, suas exportações eram sobretudo charque e couro (SHUMWAY, 2008, p. 37).
\end{abstract}

Baseado em um trecho do alvará, de 1591, emitido pelo rei D. Felipe II (um mês antes da visita inquisitorial), Sergio Buarque de Holanda (1976) fez uma grande contribuição ao relacionar a chegada do inquisidor em Pernambuco, por exemplo, ao interesse da monarquia espanhola em conter a rede comercial estabelecida pelos cristãos novos na América portuguesa. Outro exemplo, citado por Janaína Guimarães da Fonseca Silva (2007) em Modos de pensar, maneiras de viver foi o Vice-Reino do Peru que estabelecido comércio com o Brasil, entre os anos de 1591 a 1594, e o suspendeu devido ao contrabando da prata e o perigo de evasão em territórios brasileiros.
Nesse período, a religião católica tinha uma força considerável e poderia interferir em questões políticas e econômicas da metrópole e da colônia. Essa relação é pouco abordada no trabalho de Nicolas Shumway, quando se referiu ao tempo colonial. Particularmente, as divergências posteriores entre as diferentes burguesias, seja de orientações liberal ou conservadora, ficaram limitadas ao campo econômico, perdeu-se os "rastros" da influência e da cultura judaica e dos cristãos novos.

Os conflitos entre as burguesias de Buenos Aires, representada pelos portenhos conservadores, e do interior, pelos caudilhos de viés liberal, adquire uma maior intensidade com a instalação do Vice-Reinado do Rio da Prata e a criação de novos mecanismos políticoeconômicos que favoreciam ainda mais os interesses dos primeiros em contrapartida dos segundos. Como o monopólio das transações comerciais era dos portenhos, as autoridades reais tendiam a sobrepor os seus interesses sob os demais. Estabelecia-se uma lógica unilateral de poder e de riqueza concentrada na relação entre Buenos Aires e metrópole espanhola, relegando o interior a trocas comerciais menos satisfatórios e com custos mais altos devido à logística.

Cabe ressaltar que a própria burguesia de Buenos Aires nutria também rivalidades. Particular ao sistema capitalista, com o tempo, uma parcela cada vez mais diminuta gozava financeiramente de contratos exclusivos com os comerciantes europeus ligados a Coroa espanhola. Nicolas Shumway deixa bem claro em sua tese que o resultado dessas disputas comerciais, cada vez mais acirradas, reflete diretamente em disputas ideológicas e divergências políticas entre conservadores e liberais.

Nicolas Shumway aponta que as interferências do governo inglês são frequentes ao longo da história da Argentina a favor da burguesia liberal e do laisse- 
faire. Com a política de laisse-faire, os ingleses pretendiam competir pelo monopólio do comércio portenho contra os espanhóis. Porém, a entrada de produtos britânicos era questionada pelos conservadores ao alegar que a entrada dos ingleses no comércio prejudicaria as fábricas locais, sem condições de competir com a tecnologia dos produtos fabricados pela primeira potência econômica da época.

$\mathrm{Na}$ época, existia uma ampla discussão a respeito das vantagens e das desvantagens em adotar uma política protecionista para os negócios locais. A centralização dos impostos no Estado portenho posicionava as representações políticas do interior dependentes de Buenos Aires o que exprimia uma enorme vantagem para a burguesia portenha, em sua maioria, agroexportadora, contrária aos interesses de um livre comércio. $\mathrm{O}$ Estado, apesar da condição política de independência, continuava a reproduzir o paradigma econômico "monopolista", favorável a província de Buenos Aires, de orientação voltada ao mercado externo.

As relações políticas econômicas entre campocidade, na análise de Nicolas Shumway, ficaram restritas a perspectiva "de fora para dentro", em outras palavras aos interesses agroexportadores de uma burguesia liberal conservadora atreladas à dinâmica do mercado internacional. Falta ao trabalho de Nicolas Shumway, compreender as contradições internas acentuadas ao longo do tempo entre as relações campocidade, principalmente quanto aos conflitos provocados pela escassez de investimentos em determinadas áreas ou com a invasão de territórios ocupados para plantio de monoculturas para exportação. As lutas dos indígenas, dos criollos, dos negros etc. em prol dos meios de sobrevivência, relacionando-as aos fatores fundamentais de construção das ficções-diretrizes nacionais estão ausentes na obra.
A falta de confiança na cidade portuária cresceu à medida que Buenos Aires, refletindo o próprio localismo, alimentava a aspiração de controlar o interior [...] mediante o controle de taxas alfandegárias, Buenos Aires interferia de forma crescente na vida financeira do interior. Diante dessa invasão da autonomia local e da usurpação de seus lucros por meio de taxas aduaneiras, os moradores da província passaram a temer a nova hegemonia dos portenhos, temor que teria resultado quase cinquenta anos de guerras civis, começando logo depois das Guerras da Independência (SHUMWAY, 2008, p. 37).

As divergências ideológicas entre as burguesias conservadora e liberal não significavam de forma alguma que os alicerces da construção de uma identidade nacional para a Argentina foi baseada em proposições aparentemente idealistas. Pelo contrário, o que Nicolas Shumway comprova é a sobreposição de interesses materialistas para a construção da política nacional. Um terceiro limite na pesquisa de Nicolas Shumway aparece nesse momento. Não há dúvida de que o processo de construção da identidade nacional é feito por uma elite para o povo, "de cima para baixo". No entanto, isto não se restringe a uma absorção total $\mathrm{e}$ homogênea por parte do povo.

Essa discussão em history from below ("história vista de baixo") ficou ausente ao trabalho de Nicolas Shumway, concentrado apenas nas questões da classe dominante. Será que o povo não tinha os seus próprios interesses materiais para concordar ou discordar de uma determinada política de construção da identidade nacional? Qual a participação efetiva do povo como fator de pressão social para influenciar as medidas políticas aprovadas nesse sentido? E quais as influências exercidas "de baixo para cima" para o processo de invenção do argentino e da nacionalidade argentina? 


\section{Intelectuais, escritores e políticos e a construção da identidade nacional}

Há um intenso debate entre historiadores argentinos da contemporaneidade sobre as razões que levaram ao assassinato do vice-rei Santiago de Liniers. Tal acontecimento marcante na história do nacionalismo argentino foi amplamente explorado pela historiografia pelo fato de ter gerado uma reação sem precedentes por parte dos "argentinos" contra uma suposta liderança de origem francesa imposta pela Coroa espanhola. Além disso, o infortúnio acontecido ao vice-rei aguçou a rivalidade no seio das elites conservadora e liberal, pois Liniers era um dos aliados políticos do general Cornelio Saavreda, um importante representante da ala conservadora que gozava de ampla popularidade e de rivais poderosos como o advogado e jornalista Mariano Moreno e o político Juan José Paso, ambos representantes dos interesses da ala liberal. A morte de Santiago de Liniers foi interpretada como prova do desinteresse das elites liberais pelas reais necessidades do povo argentino.

Não demorou muito e do "morenismo" nasceu o Partido Unitário, que, como a denominação sugere, favorecia um governo fortemente centralizado, controlado pelas elites portenhas. Da mesma forma, o "saavedrismo" logo se transformou em um partido de oposição chamado Federalista, que favorecia a autonomia provincial e tendia a ser mais populista. Embora em principio os federalistas tivessem um compromisso com a autonomia provincial, e os unitários com o centralismo, na prática as rivalidades politicas esmaeciam essas distinções ideológicas, a tal que federalistas de Buenos Aires chegaram a ser tão implacavelmente centralistas quanto unitários mais ortodoxos (SHUMWAY, 2008, p. 75).

Conforme Halperín Donghi demostra em Politics, Economics and Society in Argentina in the Revolutionary Period, um livro notável na opinião de Nicolas Shumway, os latifundiários portenhos foram alternada- mente liberais e protecionistas, cosmopolitas e nacionalistas, dependendo, em cada momento, de qual era o lado mais promissor para seus negócios. O que realça a influência da interpretação materialista da pesquisa de Nicolas Shumway, porém evidenciar o interesse pela acumulação de capital das burguesias local em detrimento de sua opção político-ideológico sem relacionála com a dinâmica do sistema capitalista e a história mundial deixa o leitor aquém de como esses interesses eram defendidos e por que aconteciam essas mudanças, frequentemente dadas, pela imposição políticoeconômica das nações imperialistas.

Outro ponto interessante registrado pela historiografia foi o papel da liderança do político e militar José Artigas, transformado em herói nacional após a independência em 1816. Além disso, José Artigas foi responsável pela criação da primeira Constituinte (sem a participação de Buenos Aires) e da defesa da indústria local ameaçada pelos interesses britânicos. Nicolas Shumway explica que, com José Artigas, pela primeira vez, observaram-se as lutas da burguesia local contra os privilégios comerciais advindos da Espanha e da GrãBretanha.

Não obstante, segundo consta o clássico de Tulio Halperin Donghi, Una nación para el desierto argentino, depois ampliado em Proyecto y construcción de una nación, Artigas não apresenta o status de um herói nacional. Tampouco foi o primeiro a alertar sobre os privilégios comerciais, que, já eram preocupação antes de 1810, especialmente para o grupo que se nucleava em torno do consulado de comércio.

A historiografia do século XIX, aponta Nicolas Shumway, encarregou-se de criar os mitos e os heróis da futura nação Argentina. A reconstrução da imagem até então pejorativa do gaucho mostrou-se estratégica para a ressignificação do que seria o "argentino puro ou original". Os gaúchos faziam parte da rede de interess- 
es que atendia os caudilhos, representantes políticos de muita influência no interior e que disputavam o poder com os políticos portenhos. O termo especificamente representa uma das principais ficções-diretrizes do nacionalismo argentino. Para o autor, a literatura da época com Bartolomé Hidalgo e Domingo Faustino Sarmiento já tinha consciência das contraposições relacionadas à terminologia, porém, ainda hoje surgem discussões sobre a relação dos gaúchos e a nacionalidade argentina.

A peculiaridade da literatura gauchesca começa com o emprego do termo gaucho [...] O debate contemporâneo varia entre dois extremos. De um lado estão os puristas, para quem gaucho significa originalmente vagabundo, deliquente, pária: nenhum campesino que se respeitasse consentiria em ser chamado por esse termo [...] Do lado oposto, estão os autores que inclinam para o romântico, usando a palavra para caracterizar o autêntico espirito argentino, marcado pela simpatia e generosidade [...] No século XX, o termo adquiriu significado especial quando escritores nacionalistas e populistas [...] tornaram o gaucho o símbolo da Argentina autêntica, que supostamente tinha sido violada, traída e pilhada por uma classe superior gananciosa, próeuropéia e antinacional, associada a aliados estrangeiros (SHUMWAY, 2008, p. 104-6).

A leitura da obra de Nicolas Shumway passa pelos principais líderes políticos argentinos do século XIX e as suas respectivas propostas para a construção de uma identidade nacional. Um outro líder político importante para a construção do nacionalismo argentino apontado pelo autor foi o ditador Juan Manuel de Rosas. Para justificar o Estado de exceção, Juan Manuel de Rosas, em 1835, com plenos poderes políticos, levantou a necessidade urgente de se corrigir os "erros do passado" e que uma "nova Argentina" iria emergir sob o seu governo.

Sucessivamente, com a queda da ditadura Rosas exilado na Grã-Bretanha, Domingo Faustino Sarmiento assume a presidência em 1868 com a promessa de "civilizar" e trazer o "progresso" ao povo argentino. A partir daí, as condições históricas do fracasso da Argentina passam a ser explicadas pelo "atraso" causado, principalmente, pela política de impostos herdada desde o processo de colonização espanhola, no qual visava o interesse exclusivo dos portenhos. Além da importação de mão de obra escrava para os latifúndios agroexportadores e da falta de disposição para o trabalho de gaúchos e de indígenas. Para solucionar esses problemas, o ideal seria apoiar políticas que estimulassem o processo de imigração das melhores linhagens operárias europeias (especialmente a raça alemã) para as fábricas argentinas.

Entre 1852 e 1854, Justo José de Urquiza derrubou de vez a ditadura Rosas com a ajuda do Brasil. O interesse brasileiro era retirar o militar Juan Manuel de Rosas do poder pelas constantes interferências e medidas protecionistas com relação ao comércio da região da Prata. Uma nova Constituição foi aprovada em 1853 para a nova capital federal, instalada em Paraná, capital de Entre Rios, afastada de Buenos Aires.

Formula-se então o "Pacto de São Nicolau" que uniria as províncias contra as imposições conservadoras de Buenos Aires. A Argentina estava geograficamente dividida. Apesar de medidas políticas voltadas a estimular o comércio no porto do Rosário, a situação econômica das províncias mostrara-se com o tempo insustentável, sem o apoio de Buenos Aires.

As tentativas de reconciliação entre os provinciais e os portenhos trouxeram novas discussões acerca da identidade nacional. De um lado, o escritor e político Juan Bautista Alberdi que apoiava Urquiza e defendia a "tradição popular", o "nacionalismo" e posicionava-se contra os ideais do liberalismo e a favor dos caudilhos e gaúchos. Do outro, Domingo Faustino Sarmiento contra Justo José de Urquiza, este último militar e político 
defensor de que o melhor para a Argentina seria o "modelo europeizante" da "civilização e do progresso".

Em 1861, o militar, político e escritor Bartolomé Mitre foi eleito presidente da Argentina. Com relação à ampliação dos métodos de incorporação do romance nacional, o seu desempenho político foi fundamental para a abrangência do ensino público nas escolas sobre os heróis nacionais e os inimigos da nação, principalmente a justificar as constantes intervenções militares como uma "ação necessária" para salvar os argentinos do domínio bárbaro dos caudilhos.

$\mathrm{Na}$ década de 1860 , os líderes de províncias mais conservadores procuraram impor uma política de terror àqueles que apoiavam a ideia de uma Confederação que privilegiava a autoridade de Buenos Aires, uma vez que gozaria de maior representação na Câmara devido à proporção de sua população (o número de deputados era proporcional ao quantitativo populacional). Foi assassinado o caudilho Nazario Benavídez e o seu sucessor José Virasoro, da província de San Juan, assim como Justo José de Urquiza numa emboscada armada por um de seus oficiais que o enxergava como traidor da nação.

Para a maioria dos argentinos a história oficial, a versão do passado acolhida nos livros escolares, é composta de histórias liberais e portenhas. O principal criador da versão oficial foi o arqui-rival de Alberdi e Urquiza: Bartolomé Mitre - general, politico e estudioso que defendeu incansavelmente os privilégios de Buenos Aires e encarou o registro da história como mais um campo onde a cidade portenha poderia triunfar [...] Utiliza deliberadamente o passado para criar uma mitologia nacional, uma ficção-diretriz, cuja função primordial é justificar a Argentina que ele vislumbra [...] todos os caudilhos eram bárbaros; Urquiza era um caudilho como outro qualquer; logo, o governo de Urquiza sediada em Paraná representava as forças da barbárie (SHUMWAY, 2008, p. 285)
Com o caos instalado nas províncias, o governo de Bartolomé Mitre foi altamente beneficiado e os privilégios de Buenos Aires permaneceram intocáveis, explica Nicolas Shumway. A princípio, a Guerra do Paraguai foi bem aproveitada por Bartolomé Mitre que a utilizou para atacar os gaúchos (base de poder dos caudilhos), exilar inimigos políticos e também fazer fortuna com a venda de couro, carne e cavalos para as forças da Aliança (Brasil, Uruguai e Argentina).

A guerra, e a aliança com o Brasil, posteriormente, ocasionaram problemas graves e acusações de traição ao líder da nação. Bartolomé Mitré era acusado de várias improbidades políticas e administrativas, inclusive o de ter sido manipulado pelo governo brasileiro e pelos estrangeiros, gerando riquezas somente para uma pequena elite portenha. Sucintamente, agindo de encontro aos interesses nacionais.

Em contrapartida, Bartolomé Mitré castigou severamente os grupos mais abastados como os gaúchos; exterminou e expulsou os indígenas de suas terras etc. Quando Bartolomé Mitre tentou reconquistar a presidência disputando com Nicolás Avellaneda (apoiado por Sarmiento) acabou perdendo as eleições. Não aceitou a derrota nas urnas que alegava ter sido fraudada, organizou uma milícia para tomar o poder, mas foi derrotado e morto sob o julgo de uma corte marcial.

Em uma longa crítica da Historia de Belgrano, de Mitre, Alberdi prossegue sua argumentação afirmando o seguinte: Para Buenos Aires, a Revolução de Maio significava a independência da Espanha e o controle político-econômico das províncias. No caso das províncias, a Revolução de Maio significava o fim do domínio espanhol, porém uma submissão a Buenos Aires: uma reforma do colonialismo, mas não a sua abolição. 
Esse desvio da revolução provocado pela ambição irrefletida de Buenos Aires criou dois países distintos e contraditórios sob a aparência de um só: o Estado metropolitano, Buenos Aires, e o país vassalo, a República. Um governa, o outro obedece; um se beneficia da renda nacional, o outro a produz; um é afortunado, o outro miserável.

Já no século XX, Nicolas Shumway encerra a sua obra ao explicar que Perón apresentou-se com êxito como "amigo" das massas, um nacionalista, um argentino "autêntico", e sem medo de desafiar a elite liberal “anti-Argentina". Ainda hoje, segundo Shumway, a demanda do tal argentino "original" que, de forma messiânica e heroica colocasse o "trem do país" nos trilhos do progresso, continua a exercer o seu papel ambíguo na história da Argentina, tanto como uma funçãodiretriz da política atual como também uma ameaça constante ao estabelecimento de um governo institucional e democrático.

\section{Considerações finais}

Para a proposta da pesquisa no qual Nicolas Shumway havia pretendido, pode-se dizer que a alcançou com o devido mérito. Ele demonstrou profundidade nas discussões e uma extensa pesquisa documental. A invenção da Argentina, de Nicolas Shumway, demonstrou competência em sua análise materialista e estruturalista da história, sobretudo pela análise auspiciosa dos campos político e econômico; todavia não se trata de uma obra bem fundamentada no materialismo histórico.

O domínio teórico-metodológico apresentado, do que se pretendeu no plano da pesquisa, isto é, os objetivos relacionados à construção de sua narrativa histórica, são bem realizados. Essa competência, demonstrada pelo autor, faz do conjunto da obra, uma importante contribuição para a historiografia. Contudo, ao aproxi- mar-se do pensamento historicista caiu na armadilha da empatia com a classe dominante. A narrativa torna-se engessada numa perspectiva de construção histórica vista apenas de "cima", enfatizando os discursos dos "vencedores". Não há dúvidas quanto à preferência dada por Nicolas Shumway pelo olhar das elites políticas e de seus representantes em contrapartida ao limbo no qual relegou o "povo argentino" diante do processo de construção da identidade nacional.

Em geral, a obra deu conta, mas se prendeu, ao estereótipo da divisão entre portenhos e interioranos, unitários e federais. No debate, na coletânea de Chiaramonte e Carmagnani, o panorama apresenta-se de modo mais complexo. As duas das figuras mais importantes do Panteão Nacional foram interioranos, Sarmiento, sanjuanino, e Roca, tucumano. Por sinal, quem deflagra o golpe a Rosas foi um caudilho entrerriano, Juan José de Urquiza. Igualmente, muitos caudilhos foram portenhos, assim como tinha unitários que foram do interior como o general José María Paz. No caso do tucumano Juan Bautista Alberdi, apesar de ter produzido alguma literatura costumbrista gauchezca, era um liberal, que lutou contra Rosas, encabeçando a geração de 1937, na qual Sarmiento se inspirou que lutou para Buenos Aires. Portanto não antagônicos. Ele escreveu Bases y puntos de partidas, obra que se tomou como pedra basal do Estado argentino.

De antemão, talvez, o aprofundamento teórico do materialismo histórico, nas formulações explicitadas em A ideologia alemã, de Karl Marx e Friedrich Engels (2005), acerca das contradições do crescimento econômico no que concerne à relação campo-cidade, no sistema capitalista, teria sido de grande ajuda para ampliar a sua visão crítica, no sentido de apreender o "lugar", que ficou "vazio", e que deveria ter sido dado ao "povo" na história pretendida. 
Aqui, o "povo" refere-se estritamente a negação do que se considerou "elite", os não elitizados, praticamente, todos aqueles que não fizeram parte diretamente da pesquisa de Nicolas Shumway, que, pelo olhar historicista empregado, terminou "fora" da história.

O historiador não pode se eximir de sua tarefa de dar voz aos que foram silenciados pela memória oficial, mormente qual a importância dessa "presença", de um olhar visto de "baixo"? E o que significou essa ausência? Por exemplo, os gaúchos, os negros, os indígenas, as mulheres etc. qual a sua participação na construção da identidade nacional? Esse "lugar", talvez, seja responsável por uma "fatia generosa" da complexi- dade da trama, do que foi proposto, na invenção da Argentina.

Pode-se compreender, equivocadamente, que a “invenção", a “fabricação" dessa nacionalidade, nos termos apresentados, nem foi necessariamente construída, mas conduzida pelas elites, imposta "de cima para baixo", de forma tão (in) "tranquila" e "condescendente" quanto à (ou à falta de) lógica na incorporação precisa dessas ideias, alheias aos diversos interesses políticos econômicos, também culturais, dos argentinos. Desta sorte, a "hydra de muitas cabeças" teria sido facilmente (ou totalmente) manipulada pelo julgo, ou pelo "jogo", das "verdades" ideológicas da classe dominante.

\section{Referências bibliográficas}

CHIARAMONTE, José Carlos. El federalismo argentino en la primera mitad del siglo XIX. In: Marcello Carmagnani (coord.). Federalismos latinoamericanos: México/Brasil/Argentina. México: Fondo de Cultura Econômica; El Colégio de México, 1993.

. Metamorfoses do conceito de nação durante os séculos XVII e XVIII. In Marcello Carmagnani (coord.). Federalismos latinoamericanos: México/Brasil/Argentina. México: Fondo de Cultura Econômica; El Colégio de México, 1993.

DONGHI, Tulio Halperin. Una nación para el desierto argentino. Disponível em: < http://www.terras.edu.ar/ biblioteca/14/14HLA_Halpering_Donghi_Unidad_2.pdf>. Acesso em: 13 set. 2016.

HOBSBAWM, Eric; TERENCER, Ranger. A invenção das tradições. 6 ed. Rio de Janeiro: Paz e Terra, 1997. HOLANDA, Sergio Buarque de. (dir.) História Geral da Civilização Brasileira. Tomo I, A Época Colonial. Vol. 1. Do Descobrimento à Expansão Territorial. São Paulo - Rio de Janeiro: DIFEL, 1976.

LINEBAUGH, Peter; REDIKER, Marcus. A hidra de muitas cabeças: marinheiros, escravos, plebeus e a história oculta do Atlântico Revolucionário. São Paulo: Companhia das Letras, 2008.

MARX, Karl; ENGELS, Friedrich. A ideologia alemã : Feuerback - a contraposição entre as cosmovisões materialista e idealista. São Paulo: Martin Claret, 2005.

SHUMWAY, Nicolas. A invenção da Argentina: história de uma ideia. São Paulo: USP; Brasília: UnB, 2008. SILVA, Janaína Guimarães da Fonseca. Modos de pensar, maneiras de viver: cristãos novos em Pernambuco no século XVI. Mestrado. UFPE, 2007. 